\title{
Projected change in Frequency, Intensity and Duration of Atmospheric Temperature Inversions for Southeast Australia
}

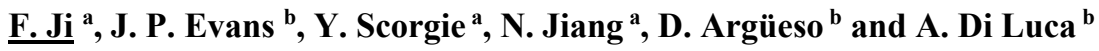 \\ ${ }^{a}$ New South Wales Office of Environment and Heritage, Sydney, Australia \\ ${ }^{b}$ Climate Change Research Centre and ARC Centre of Excellence for Climate System Science, University of \\ New South Wales, Sydney, Australia \\ Email:fei.ji@environment.nsw.gov.au
}

\begin{abstract}
Temperature inversions occur when temperature increases with altitude in the lower atmosphere. An inversion can lead to pollution events such as smog being trapped close to the ground, with possible adverse effects on health, and may result in violent thunderstorm and freezing rain in the cold season. The effect of temperature inversions means that any trends in their frequency, intensity (temperature gradient within the inversion layer), and duration under global warming have implications for sectors such as air pollution management or agriculture.
\end{abstract}

In this study, we used outputs of 12 historical and future Regional Climate Model (RCM) simulations (each covering three time periods: 1990-2009, 2020-2039, and 2060-2079) from the NSW/ACT Regional Climate Modelling (NARCliM) project to investigate changes in low level temperature inversions. For each $10 \mathrm{~km}$ by $10 \mathrm{~km}$ grid cell within the NARCliM domain, temperature inversions were identified by checking the vertical temperature profile in 3-hourly data. Characteristics of the inversions such as height, temperature at the top and bottom of the inversion layer were recorded. Temperature inversions for the two future periods (20202039 and 2060-2079) are compared to the historic period (1990-2009) to investigate the changes in frequency, intensity, and duration of inversions for each of the 12 simulations.

The results show that there is a substantial increase in the frequency and duration of temperature inversions and a decrease in the intensity of the temperature inversion for most simulations for southeast Australia. The largest differences between simulations were associated with the driving GCMs, suggesting that the large scale circulation plays a dominant role in forming and sustaining low level temperature inversions.

Keywords: Temperature inversion, NARCliM, ensemble mean 
Ji et al., Projected changes in frequency, intensity and duration of temperature inversion for southeast Australia

\section{INTRODUCTION}

In meteorology, a temperature inversion is a deviation from the normal change of atmospheric temperature with altitude in the troposphere, with temperatures increasing with height. Due to associated stability and resistance to vertical mixing, an inversion can lead to pollution such as smog being trapped close to the ground, with possible adverse effects on health. An inversion can also suppress convection by acting as a "cap". If this cap is broken for any of several reasons, convection of any moisture present can then erupt into violent thunderstorms. Temperature inversions can also notoriously result in freezing rain in cold climates. Temperature inversions are normally identified by using vertical temperature profiles. As few weather stations provide upper air sounding data, remote sensing data have been used to identify temperature inversion layers (Liu 2003, 2006).

Temperature inversions have mostly been investigated in the context of case studies and group events. Studies have investigated the evolution and characteristics of temperature inversions (Whiteman et al 1999, Connolley 1996), and the relationship between temperature inversion and atmospheric circulation (Bailey et al. 2011). A number of studies have examined the impact of temperature inversions on precipitable watervapour (Tomasi 1977), particulate matter and gaseous air pollutant concentrations (Wallace et al, 2009, Olofson et al, 2009, Rendon et al, 2014) and human health (Beard et al, 2012).

The climate of temperature inversion has recently attracted research interest due to its impacts. Seasonal variation of temperature inversions have been investigated by a number of studies (Nodzu et al 2006, Kassomenos and Koletsis 2005). The climate of temperature inversions has been also investigated by Pietroni, et al, 2014 and Bourne et al. 2010. However, these temperature inversion climate related studies are all based on observations (station data or remote sensing). Future projections of temperature inversions have not yet been seen in the literature.

The New South Wales (NSW)/Australian Capital Territory (ACT) Regional Climate Modelling (NARCliM) project aimed to deliver robust climate change projections for southeast Australia at a scale relevant for localscale impact studies and decision-making (Evans et al. 2014). The project provides vertical temperature profiles at 3 hourly intervals, which can be used to identify temperature inversions and investigate their characteristics.

The aim of this study is to answer questions about future changes in the characteristics of temperature inversions based on an ensemble of simulations which span a range of plausible future climates. These questions include whether there are any changes in frequency of temperature inversions, any changes in inversion intensity and duration, and what differences there are in the inversion projections between different simulations.

\section{DATA}

The vertical temperature profiles are from the NARCliM project. In NARCliM, simulations from four GCMs were used to drive three RCMs to form a 12-member GCM/RCM ensemble (Evans et. al. 2014). The four selected GCMs are MIROC3.2, ECHAM5, CCCMA3.1, and CSIRO-MK3.0. For the future projections the SRES A2 emission scenario was used. The three selected RCMs are three physics scheme combinations of the WRF model. Each simulation consists of three 20-year runs (1990-2009, 2020-2039, and 2060-2079). The 4 GCMs and 3 RCMs were chosen based on a number of criteria: i) adequate performance when simulating historic climate; ii) most independent; iii) cover the largest range of plausible future precipitation and temperature changes for Australia (only for selection of GCMs). We acknowledge that the results are model dependent (as all model studies are) but through the use of this carefully selected ensemble we have attempted to minimize this dependence. By using this model selection process we have shown that it is possible to create relatively small ensembles that are able to reproduce the ensemble mean and variance from the parent large ensemble as well as minimize the overall error (Evans et al., 2013a). The model domain covers the Coordinated Regional Climate Downscaling Experiment (CORDEX) (Giorgi et al., 2009) Australasian region with $50 \mathrm{~km}$ and the NARCliM domain with $10 \mathrm{~km}$ grid sizes. Both domains have 30 vertical levels spaced closer together in the planetary boundary layer.

Some initial evaluation of NARCliM simulations shows that RCMs have strong skill in simulating the precipitation and temperature of Australia, with a small cold bias and overestimation of precipitation on the Great Dividing Range (Evans et al, 2013b, Ji et al. 2015). The differing responses of the different RCMs confirm the utility of considering model independence when choosing the RCMs. The RCM response to large scale modes of variability also agrees well with observations. Recent precipitation and temperature evaluations indicated the WRF model has strong skill to simulate regional climate for southeast Australia (Evans et al 2013b, Ji et al 2015). Through these evaluations we found that while there is a spread in model predictions, all models perform adequately with no single model performing the best for all variables and 
Ji et al., Projected changes in frequency, intensity and duration of temperature inversion for southeast Australia

metrics. The use of the full ensemble provides a measure of robustness such that any result that is common through all models in the ensemble is considered to have higher confidence. However, there has been no evaluation of the model performance specifically for temperature inversions.

For ease of reference in this paper, the simulations driven by the same GCM were referred to as GCM simulations, the simulations using the same RCM were referred to as RCM simulations. In total, there were 4 GCM simulations (average of three members) and 3 RCMs simulation (average of four members). The analyses in this study are based on the outputs from these simulations.

\section{METHODS}

For each grid within the NARCliM domain for each time interval in the output, the temperature profile below $500 \mathrm{hPa}$ was checked to identify any low level temperature inversion layers, and the temperature inversion parameters (temperature, height, pressure at the top and bottom of the inversion layer) were recorded.

Inversion parameters of interest include inversion depth, temperature difference, and strength. Inversion depth is the distance from the bottom to the top of the inversion. The inversion temperature difference is therefore the temperature change between the top and bottom of the inversion, as defined by the inversion depth. Inversion intensity or strength in this study is defined as the temperature difference over the inversion depth $(\mathrm{dT} / \mathrm{dZ})$.

Frequency of temperature inversion is defined as the number of time periods with temperature inversion divided by the total number of time periods ( 8 times a day for 20 years). The mean duration of temperature inversion is calculated by the total length of temperature inversion divided by the number of temperature inversions. The frequency, intensity and duration for each grid within the NARCliM domain are calculated for each of the 12 NARCliM ensemble members, for each of three time periods. The change in temperature inversion characteristics for the near future are expressed as differences between the 2020-2039 epoch and the 1990-2009 base case epoch. Similarly changes in characteristics for the far future are based on differences between the 2060-2079 and 1990-2009 epochs. The results for each ensemble member were averaged to get the ensemble mean.

\section{RESULTS}

\subsection{Mean and Change in Frequency}

Changes in the frequency of temperature inversions were calculated for each of the 12 ensemble members. The ensemble mean is presented in Fig.1. There is a weak west-east gradient of the frequency of temperature inversion for land areas for the period of 1990-2009. There are slightly higher values over the inland deserts and relatively lower frequency over the Great Dividing Range. It is almost uniform in values for most of the domain at around $60 \%$. These indicate that WRF simulations show temperature inversions are quite common in southeast Australia. Over ocean, the frequency of temperature inversion is much lower than that for land areas. The higher frequency can be observed over the Great Australian Bight and lower values are in the northern Tasman Sea.
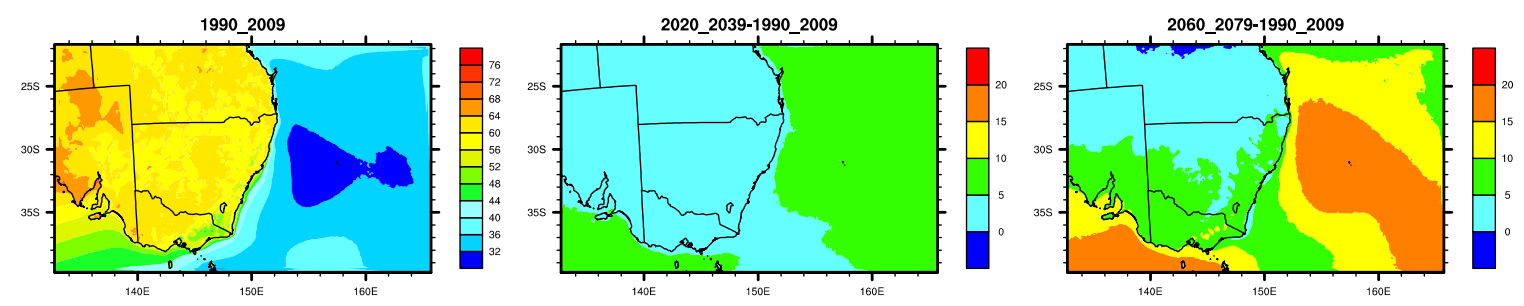

Figure 1. Ensemble mean frequency of temperature inversion for 1990-2009, and changes in frequency for 2020-2039 and 2060-2079 relative to 1990-2009 (unit: \%).

The changes in frequency for 2020-2039 relative to 1990-2009 are quite small for the whole domain, with 0$5 \%$ increase for land areas and the southern Tasman Sea, and 5-10\% increase for the northern Tasman Sea and the Great Australian Bight.

The changes in frequency for 2060-2079 relative to 1990-2009 are larger than those for 2020-2039 relative to 1990-2009. For land areas, there is a small increase (0-5\%) or even a small decrease for the northern domain, but a $5-10 \%$ increase for the southern domain. For the ocean areas, $15-20 \%$ increases are projected for the 
Ji et al., Projected changes in frequency, intensity and duration of temperature inversion for southeast Australia

Great Australian Bight and the northern Tasman Sea, with some increase (5-10\%) for the southern Tasman Sea.

\subsection{Mean and Change in Intensity}

The mean intensity of temperature inversions for land areas is generally large with more than $8{ }^{\circ} \mathrm{C} / \mathrm{km}$ for most areas. The largest value of mean intensity can be above $12{ }^{\circ} \mathrm{C} / \mathrm{km}$. Lower values $\left(2-4{ }^{\circ} \mathrm{C} / \mathrm{km}\right)$ are projected along the Great Dividing Range. The intensity over ocean areas are generally smaller, with less than $1{ }^{\circ} \mathrm{C} / \mathrm{km}$ for the northern Tasman Sea, $2-4{ }^{\circ} \mathrm{C} / \mathrm{km}$ for the southern Tasman Sea and the Great Australian Bight respectively.

The changes in mean intensity for 2020-2039 relative to 1990-2009 are generally small with 0-5\% decrease in intensity for most land areas and the southern Tasman Sea, small increases (0-5\%) for the Great Dividing Range and the Great Australian Bight, and 5-10\% increase for the northern Tasman Sea.

Projected changes in intensity between 2060-2079 and 1990-2009 are much larger than those between 20202039 and 1990-2009. For the land areas, large decreases in intensity (10-15\%) are projected for the northern domain and a $0-5 \%$ increase for the southern domain, and 5-10\% increase for Great Dividing Range and high topography areas in South Australia. For the ocean areas, larger increases (above 10\%) are projected for the northern Tasman Sea, 5-10\% increases for the Great Australian Bight, and more than 10\% decreases for the Southern Tasman Sea.
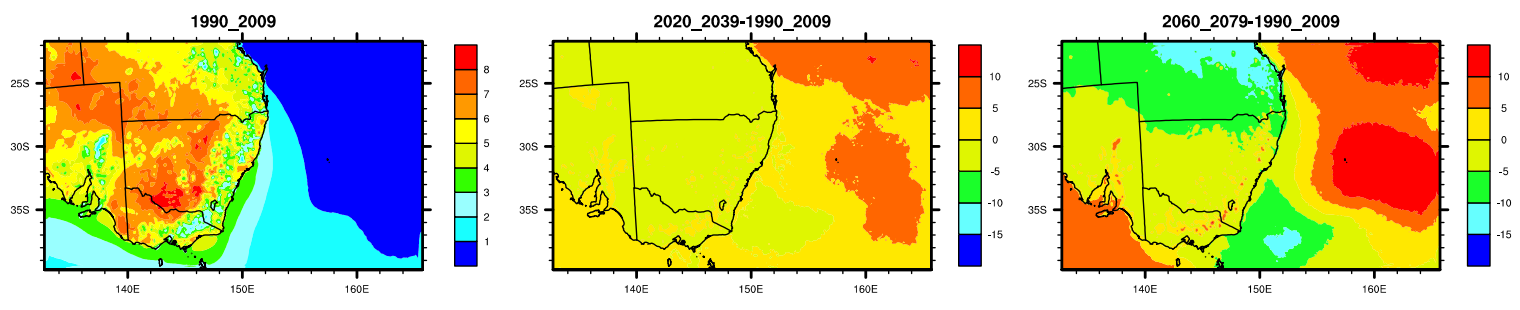

Figure 2. Ensemble mean intensity of temperature inversion for 1990-2009 (unit: ${ }^{\circ} \mathrm{C} / \mathrm{km}$ ), and changes in intensity for 2020-2039 and 2060-2079 relative to 1990-2009 (unit: \%)

\subsection{Mean and Change in Duration}

There is a weak gradient in the duration of temperature inversions for the land areas with duration of 16-18 hours for the western domain, 12-14 hours for the Great Dividing Range, and 14-16 hours elsewhere. For the ocean areas, temperature inversions generally last more than 20 hours in the Great Australian Bight, 14-16 hours over the southern Tasman Sea and 12-14 hours over the northern Tasman Sea.

There are very small (less than 5\%) projected increases in duration for 2020-2039 relative to 1990-2009 across the domain except for the Great Australian Bight where the increases can be above $8 \%$. There are larger projected changes in duration for 2060-2079 relative to 1990-2009. For land areas there is clear northeast-southwest gradient with small negative change in the north, 15-20\% increase in duration for southern land areas. For ocean areas, duration of temperature inversions is projected to increase up to $20-25 \%$ for the Great Australian Bight, about $10-15 \%$ for the northern Tasman Sea and $5-10 \%$ for the Southern Tasman Sea.
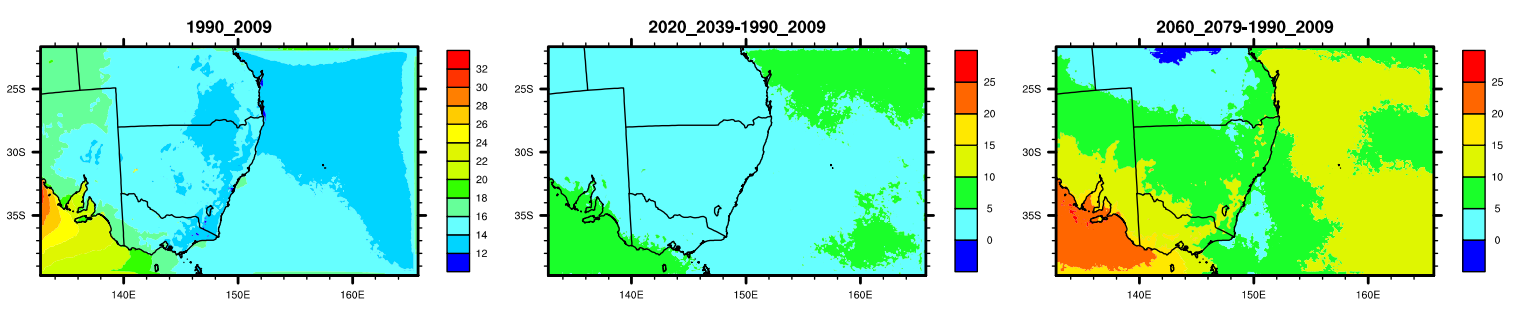

Figure 3. Ensemble mean duration of temperature inversion for 1990-2009, and changes in duration for 2020-2039 and 2060-2079 relative to 1990-2009 (unit: hour).

\subsection{Difference between simulations}

Changes in frequency, intensity and duration of temperature for 2020-1990 relative to 1990-2009 are generally small; however, those for 2060-2079 relative to 1990-2009 are larger. Now we focus on the far 
Ji et al., Projected changes in frequency, intensity and duration of temperature inversion for southeast Australia

future time period (2060-2079) to discuss projections in the RCM simulations with different GCM inputs and with different configurations.

\section{Frequency of temperature inversions}

The changes in the frequency of temperature inversions show large differences across GCM simulations, especially for ocean areas (Figure 4). Simulations based on ECHAM project more than 20\% increase in frequency for the northern Tasman Sea which is about double the changes for those based on the MIROC model. Simulations using CCCMA inputs project more than $20 \%$ increase in the Great Australian Bight, which is much higher than the other three simulations. Simulations based on ECHAM and CCCMA project a large increase for the southern Tasman Sea while CSIRO and MIROC project a decrease or little change for the same areas. For land areas, a south-north gradient of changes in frequency is consistent in the four GCM simulations, however, the magnitude of the gradient is quite different with largest gradient for MIROC simulations, followed by CCCMA and ECHAM simulations. All simulations project a larger increase (10\%) in frequency for the southern land domain.

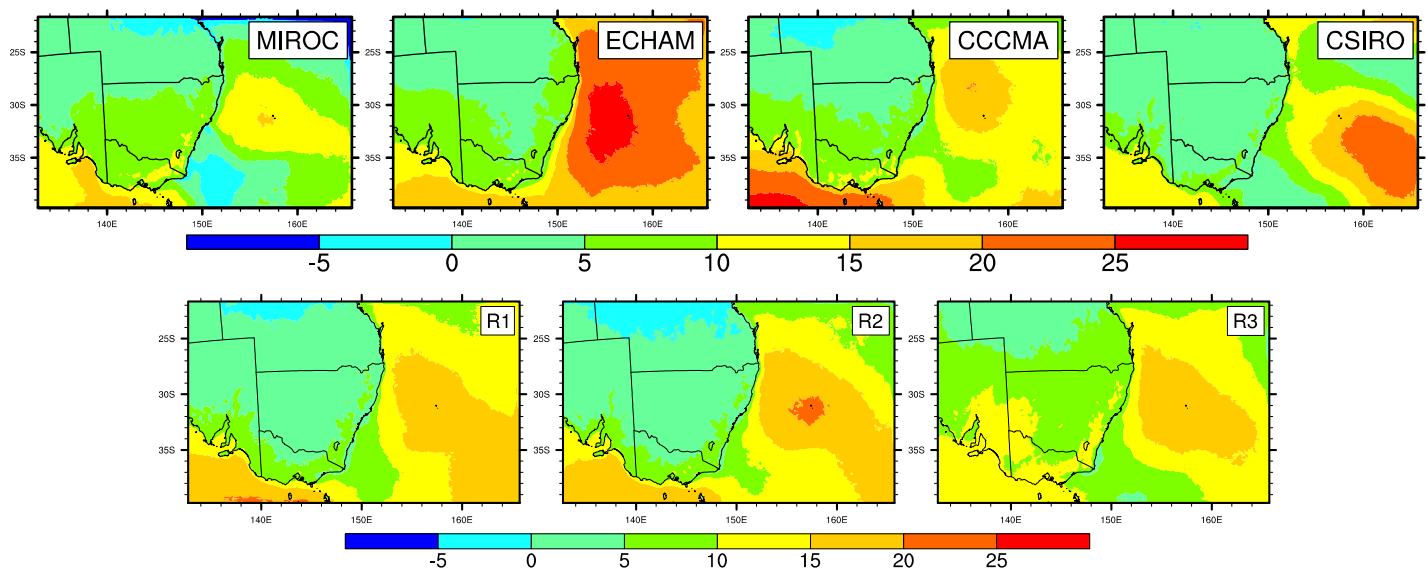

Figure 4. Mean changes in frequency for 2060-2079 relative to 1990-2009 for 4 GCM and 3 RCM simulations (unit: \%).

The differences between the three RCM simulations (average of four members) are much smaller than those between GCM simulations (average of three members). They all project a south-north gradient in changes of frequency for land areas, a large increase for the northern Tasman Sea and the Great Australian Bight, and small increase for the southern Tasman Sea, although R3 simulation project about 5\% greater change for land areas and 5\% lower change for the Great Australian Bight.

\section{Intensity of temperature inversion}

There is little similarity among changes in the mean intensity of projected temperature inversions across GCM simulations. All simulations project a decrease in intensity for the southern Tasman Sea and increases in intensity for the Great Australian Bight, however their change magnitudes are highly different. All simulations project an increase in intensity along the Great Dividing Range and high topography areas in South Australia, although most simulations except for CSIRO project a decrease in intensity for most land areas.

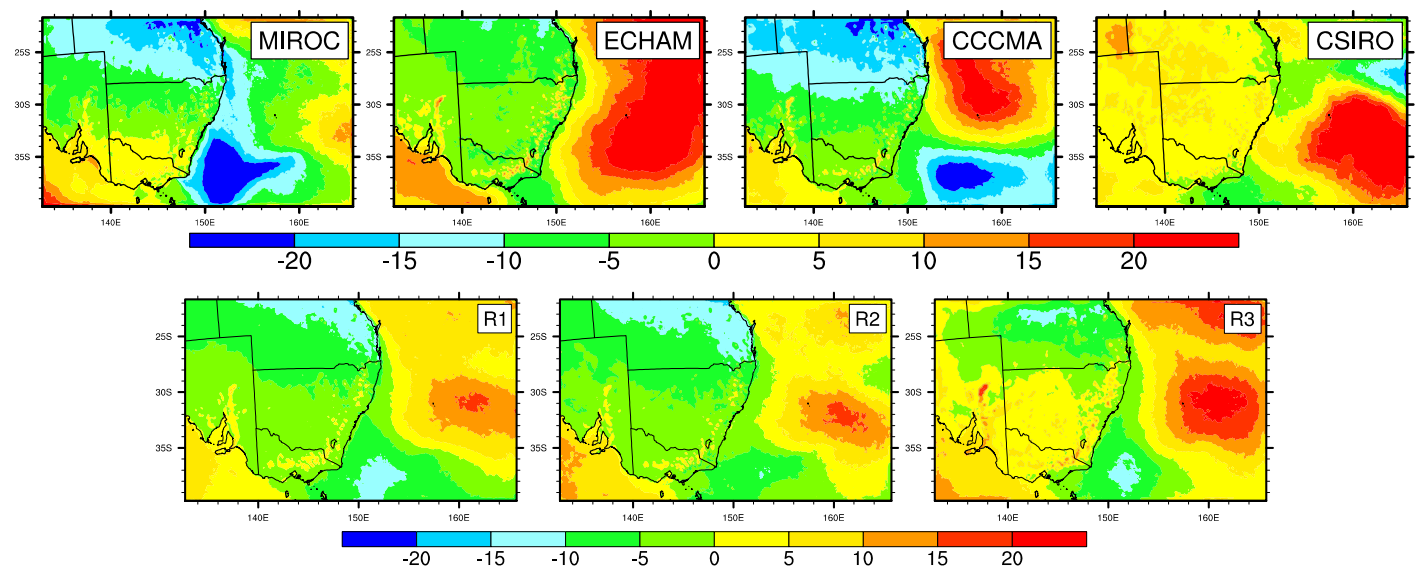

Figure 5. Mean changes in intensity of temperature inversion for 2060-2079 relative to 1990-2009 for 4

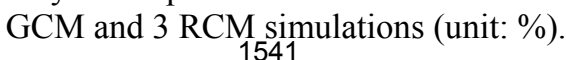


Ji et al., Projected changes in frequency, intensity and duration of temperature inversion for southeast Australia

The changes in mean intensity of temperature inversions projected by the $3 \mathrm{RCM}$ simulations (average of 4 members) are similar. For land areas, all RCMs project a more than $10 \%$ decrease in intensity in the northeast domain, and a southwest to northeast gradient in changes of intensity with the smallest increase or even a decrease in the north. RCM simulations also projected small increases in intensity along the Great Dividing Range. For ocean areas, all RCM simulations project a more than 10\% decrease for the southern Tasman Sea, a more than 5\% increase for Great Australian Bight and more than 15\% increase for northern Tasman Sea.

\section{Duration of temperature inversion}

Changes in the mean duration of temperature inversions are somewhat similar across GCM simulations. They all project little change for the northern land domain, and more than $10 \%$ increase in duration for southern domain. The southwest to northeast change gradient is also consistent in all simulations. The largest differences in the projected changes of duration across 4 GCM simulations are observed in the ocean areas. The MIROC and CSIRO simulations project a decrease in duration for the southern Tasman Sea while ECHAM and CCCMA project the opposite. CSIRO projects a small increase in duration (less than 10\%) for the Great Australian Bight, but the other three simulations projected a large increase in duration (above 20\%).

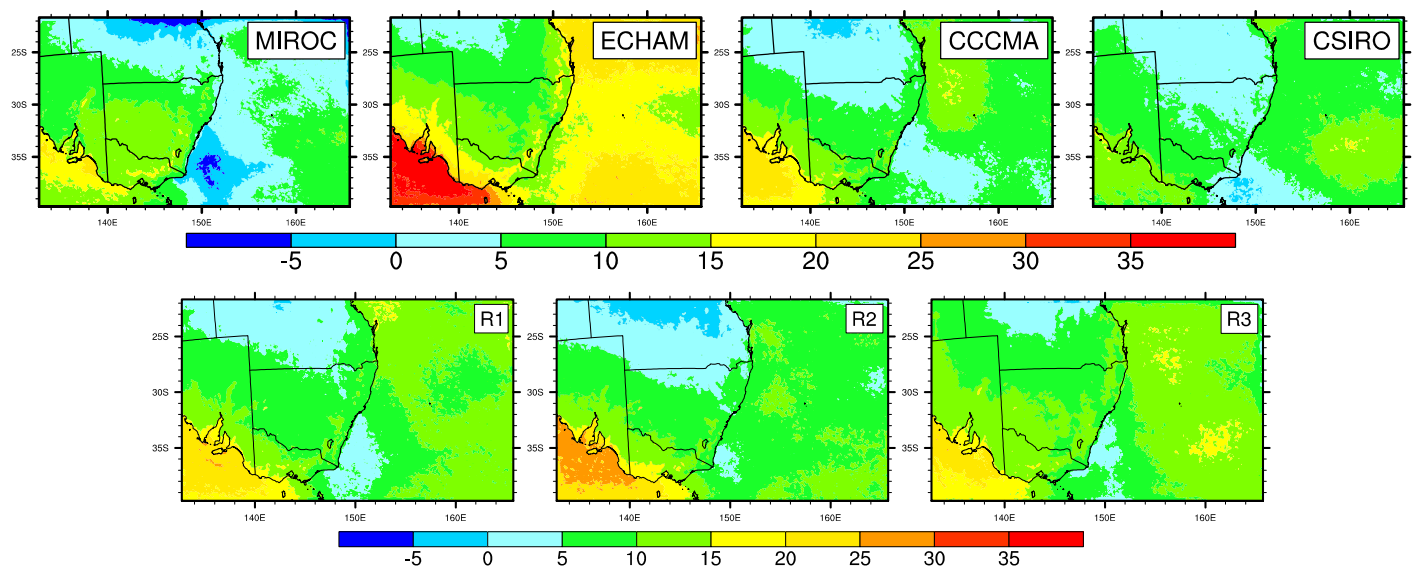

Figure 6. Mean changes in duration for 2020-2039 and 2060-2079 relative to 1990-2009 for 4 GCM and 3 RCM simulations (unit: \%).

Differences of changes in mean duration across $3 \mathrm{RCM}$ simulations are much smaller than those across 4 GCM simulations. The pattern of projected change is almost identical across the whole domain in all three configurations, although there are a few differences in change magnitude.

\section{DISCUSSION AND CONCLUSIONS}

The results shown in this paper are the ensemble mean and change in ensemble mean. The results for each of the ensemble members show that there is moderate consistency in a projected increase in the frequency and duration of low level temperature inversions below $500 \mathrm{hPa}$. However, there is low consistency for the mean projection of a decrease in intensity of the temperature inversions, indicating that there are large uncertainties with the intensity projections.

The three RCM simulations generally show similar patterns for changes in frequency, intensity and duration, however, large differences are observed in changes in frequency, intensity and duration between simulations with different GCM inputs. This suggests that the large scale circulation plays a dominant role in forming and sustaining low level temperature inversions.

Results for the ensemble mean show that diverse changes in frequency, intensity and duration are projected for different areas. For the northern land areas, little change in frequency and duration are projected but with a large decrease in intensity. However, larger increases in frequency and duration are projected for the southern land areas, but their intensity are projected to only slightly decrease. For ocean areas, a large increase in frequency, intensity and duration is projected for the Great Australian Bight and the northern Tasman Sea. Also, a small decrease in intensity and a small increase in frequency and duration are projected for the southern Tasman Sea.

\section{ACKNOWLEDGMENTS}

This work is made possible by funding from the NSW Environmental Trust for the ESCCI-ECL project, the NSW Office of Environment and Heritage lead NSW/ACT Regional Climate Modelling Project (NARCliM), 
Ji et al., Projected changes in frequency, intensity and duration of temperature inversion for southeast Australia

and the Australian Research Council as part of the Future Fellowship FT110100576 and Linkage Project LP120200777. The modelling work was undertaken on the NCI high performance computers in Canberra, Australia, which is supported by the Australian Commonwealth Government.

\section{REFERENCES}

Bailey A., Chase TN, Cassano JJ, and Noone D (2011) Changing Temperature Inversion Characteristics in the U.S. Southwest and Relationships to Large-Scale Atmospheric Circulation. J. Appl. Meteor. Climatol., 50, 1307-1323. doi: 10.1175/2011JAMC2584.1

Beard JD, Beck C, Graham R, Packham SC, Traphagan M, Giles RT, and Morgan JG (2012). Winter temperature inversion and emergency department visits for asthma in Salt Lake County, Uta, 2003-2008. Environmental Health Perspectives, Vol 120(10), p1385-1390. Doi: 10.1289/ehp.1104349

Bourne S.M., Bhatt U.S., Zhang J., Thomand R. (2010), Surface-based temperature inversions in Alaska from a climate perspective, Atmospheric Research, Vol 95(2-3), P353-366, doi:10.1016/j.atmosres.2009.09.013

Connolley W. M. (1996). The Antarctic Temperature Inversion. International Journal of Climatology, Vol16 (12), p1333-1342, DOI: 10.1002/(SICI)1097-0088(199612)16:12<1333::AID-JOC96>3.0.CO;2-6

Evans JP, Ji F, Abramowitz G, Ekstrom M (2013a) Optimally choosing small ensemble members to produce robust climate simulations. Environmental Research Letters, 8, 044050, doi:10.1088/17489326/8/4/044050

Evans JP, Fita L, Argüeso D and Liu Y (2013b) Initial NARCliM evaluation. In Piantadosi, J., Anderssen, R.S. and Boland J. (eds) MODSIM2013, 20th International Congress on Modelling and Simulation. Modelling and Simulation Society of Australia and New Zealand, December 2013, pp. 2765-2771.

Evans JP, Ji F, Lee C, Smith P, Argüeso D, Fita L (2014) Design of a regional climate modelling projection ensemble experiment - NARCliM, Geosci Model Dev 7(2), 621-629, doi: 10.5194/gmd-7-621-2014

Giorgi, F., Jones, C., and Asrar, G. R.: Addressing climate information needs at the regional level: the CORDEX framework, WMO Bull., 58, 175-183, 2009.

Ji F., Evans JP., Teng J., Scorgie Y., Argueso D., and Di Luca A. (2015) Evaluation of long-term precipitation and temperature WRF simulations for southeast Australia. Climate Research, under review.

Kassomenos PA and Koletsis IG (2005) Seasonal variation of the temperature inversions over Athens, Greece. International Journal of Climatology, Vol 25(12), P 1651-1663, DOI: 10.1002/joc.1188

Liu YH and Key JR. (2003) Detection and Analysis of Clear-Sky, Low-Level Atmospheric Temperature Inversions with MODIS. J. Atmos. Oceanic Technol., 20, 1727-1737. doi: 10.1175/15200426(2003)020<1727:DAAOCL > 2.0.CO;2

Liu YH and Key JR., Schweiger A, and Francis J (2006) Characteristics of Satellite-Derived Clear-Sky Atmospheric Temperature Inversion Strength in the Arctic, 1980-96. J. Climate, 19, 4902-4913.

Nodzu, MI; Ogino, SY; Tachibana, Y; Yamanaka, MD (2006). Climatological description of seasonal variations in lower-tropospheric temperature inversion layers over the Indochina Peninsula. Journal of climate, vol 19 (13), P 3307-3319, doi:10.1175/JCLI3792.1

Olofson, K. FG, Andersson, PU., Hallquist, M., Ljungström, E., Tang, L., Chen, DL,. Pettersson Jan B.C (2009) Urban aerosol evolution and particle formation during wintertime temperature inversions. Atmospheric Environment. Vol 43 (2), P 340-346 doi:10.1016/j.atmosenv.2008.09.080

Pietroni I, Argentini S, Petenko I. (2014) One Year of Surface-Based Temperature Inversions at Dome C, Antarctica. Boundary-Layer Meteorology, Vol 150 (1), p 131-151, DOI 10.1007/s10546-013-9861-7

Rendón AM., Salazar JF., Palacio CA., and Wirth V., and Brötz B. (2014) Effects of Urbanization on the Temperature Inversion Breakup in a Mountain Valley with Implications for Air Quality. J. Appl. Meteor. Climatol., 53, 840-858. doi: 10.1175/JAMC-D-13-0165.1

Tomasi C. (1977) Precipitable Water Vapor in Atmospheres Characterized by Temperature Inversions. J. Appl. Meteor., 16, 237-243. doi: 10.1175/1520-0450(1977)016<0237:PWVIAC $>2.0 . C O ; 2$

Wallace J, and Kanaroglou P. (2009) The sensitivity of OMI-derived nitrogen dioxide to boundary layer temperature inversions. Atmospheric Environment, Vol43 (22-23), P3596-3604 doi:10.1016/j.atmosenv.2009.03.049

Whiteman C. D, Bian XD, and Zhong SY (1999) Wintertime Evolution of the Temperature Inversion in the Colorado Plateau Basin. J. Appl. Meteor., 38, 1103-1117. doi: 10.1175/15200450(1999)038<1103:WEOTTI $>2.0 . \mathrm{CO} ; 2$ 